\title{
Flow Injection Amperometric Evaluation of Trolox Equivalent Antioxidant Capacity of Chocolates with Different Cocoa Content at a Boron-Doped Diamond Electrode
}

\author{
Tahir Arbneshi'®, \\ Arbër Frangu ${ }^{\top} \odot$, \\ Michaela Frühbauerová®, \\ Libor Červenkaº, \\ Liridon Berisha ${ }^{1} \odot$, \\ Kurt Kalcher ${ }^{3}$ and \\ Milan Sýs ${ }^{2 *}$ (]
}

'Department of Chemistry, Faculty of Mathematics and Natural Sciences, University of Prishtina, Str. Mother Teresa, 10000 Prishtina, Republic of Kosovo

2Department of Analytical Chemistry, Faculty of Chemical Technology, University of Pardubice, Studentská 573, 53210 Pardubice, Czech Republic

${ }^{3}$ Institute of Chemistry-Analytical Chemistry, Karl Franzens University, Universitaetsplatz 1, $8010 \mathrm{Graz}$, Austria

Received: 15 September 2020 Accepted: 6 May 2021

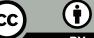

\footnotetext{
*Corresponding author:

Phone: +420466037034

Fax: +420466037279

E-mail:milan.sys@upce.cz
}

\begin{abstract}
SUMMARY
Research background. The objective of this paper is to introduce an instrumentally simple analytical tool for determination of cocoa solid content in chocolates. This electroanalytical method is based on amperometric oxidation of all present antioxidants in chocolates at boron-doped diamond electrode (BDDE) that is integrated in a flow injection analysis (FIA) wall-jet electrode system.

Experimental approach. As part of optimisation, thirteen commonly occurring antioxidants were investigated using cyclic voltammetry at the BDDE in $0.1 \mathrm{~mol} / \mathrm{L}$ phosphate buffer with different methanol $(\mathrm{MeOH})$ content. Working parameters, such as $\mathrm{MeOH}$ volume fraction, flow rate and detection potential, were optimised. Principally, the height of the oxidation peak (current response) representing the oxidation of the sum of antioxidants (total antioxidant content; TAC) was expressed as Trolox equivalents.

Results and conclusions. For analytical purpose, a linear range from 5 to $100 \mathrm{mg} / \mathrm{L}$ described by regression equation and characterised by high correlation coefficient $\mathrm{R}^{2}=0.9994$ was achieved. Obtained high positive correlation between the determined values of Trolox equivalent antioxidant capacity (TEAC) and cocoa mass fractions characterised by correlation coefficient of 0.9187 for eight randomly selected samples (one white, two milk, and five dark chocolates) confirmed that cocoa solids represent the main source of antioxidants (reducing agents).

Novelty and scientific contribution. The research demonstrates that TEAC values could be considered as an additional marker of cocoa content in the chocolate analysis to the commonly used theobromine (authenticity of food products). The developed FIA could therefore serve as simple analytical tool in the food quality control.
\end{abstract}

Key words: Trolox equivalent antioxidant capacity, amperometry, boron-doped diamond electrode, flow injection analysis, cocoa mass fraction in chocolate

\section{INTRODUCTION}

Chocolate is a favourite food product made from cocoa beans that is consumed as sweets or beverage and to flavour or coat various confectionery and bakery products (1). Generally, the chocolate is divided into three main categories, namely dark, milk and white chocolate $(1,2)$. Dark chocolate usually contains $50-90 \%$ cocoa solids, cocoa butter and sugar, whereas milk chocolate contains $10-50 \%$ cocoa solids, cocoa butter, milk in some form and sugar. White chocolate does not contain any cocoa solids and is made simply of cocoa butter, sugar and milk powder (3). Lower quality chocolates may also contain butter fat, vegetable oil or artificial colours or flavours. According to EU legislation (2000/36/ ES), the last-mentioned type must not be labelled as chocolate (4). U.S. Food and Drug Administration (FDA) issued an order that semisweet chocolate must contain a minimum of $35 \%$ chocolate liquor (5).

In the recent past, Czech Agriculture and Food Inspection Authority revealed the sad fact that most commercially available chocolates do not have the declared content of cocoa solids in order to be classified as a regular chocolate. Moreover, the statutory minimum content of cocoa solids was missing in some chocolate drinks (6). These unsatisfactory 
reports demonstrate the urgency to develop a simple analytical method applicable in the chocolate analysis.

Theobromine (TBR) is the primary alkaloid contained in cocoa powder and chocolate. Since TBR ranges from $26 \mathrm{~g} / \mathrm{kg}$ in cocoa to $140 \mathrm{mg} / \mathrm{kg}$ in cocoa butter, this alkaloid can be considered as a marker of cocoa content (7). Determination of fat-free cocoa solids is performed using a protocol ČSN 56 0578, based on the HPLC analysis (8).

In addition to TBR, dark chocolate is rich in minerals, such as potassium, iron, magnesium, copper, manganese and zinc. The cocoa in dark chocolate also contains antioxidants called flavonoids, which may provide several health benefits $(3,9)$. Assuming that cocoa powder and cocoa butter are the only sources of antioxidants, it is possible to use the total antioxidant content (TAC) as another potential marker of cocoa content (10). Phenolic compounds, flavours (vanillin and ethylvanillin) and alkaloids (TBR and caffeine) present in chocolate represent reducing agents that can be electrochemically oxidised at carbon-based working electrodes (11-14).

Due to an insignificant passivation of the electrode surface, a boron-doped diamond electrode (BDDE) was integrated into wall-jet flow cell to find out whether a simple flow injection analysis (FIA) with amperometric detection could be used for evaluation of dark chocolates (15). A correlation (R or $\mathrm{R}^{2}$ ), known as a statistical measure describing a relationship between two variables (16), represented ideal tool to clarify the dependence between the declared cocoa content and TAC values in numerous dark chocolate samples.

\section{MATERIALS AND METHODS}

\section{Chemicals and reagents}

Analytical standards of $\geq 99.0 \%$ L-ascorbic acid, $\geq 98.0 \%$ caffeic acid, $99.0 \%$ caffeine, $\geq 99 \%$ trans-cinnamic acid, $\geq 98 \%$ (-)-epicatechin, $97 \%$ ( \pm )-6-hydroxy-2,5,7,8-tetramethylchromane-2-carboxylic acid (Trolox), $\geq 95 \%$ chlorogenic acid, 97.5-102.5\% gallic acid, $\geq 97.0 \%$ kaempferol, $\geq 98 \%$ (+)-catechin hydrate, $\geq 95 \%$ naringin, $\geq 98 \%$ sinapic acid, $\geq 98.0 \%$ theobromine and $\geq 97 \%$ vanillin were purchased from Sigma-Aldrich, Merck (Prague, Czech Republic). All voltammetric measurements were performed in their $1.0 \mathrm{mmol} / \mathrm{L}$ aqueous solutions of $0.1 \mathrm{~mol} / \mathrm{L}$ phosphate buffer, $\mathrm{pH}=7.0$, prepared from sodium dihydrogen phosphate dihydrate and disodium hydrogen phosphate, both obtained from Lach-Ner, Ltd. (Neratovice, Czech Republic). Due to low solubility, naringin, (+)-catechin, (-)-epicatechin and kaempferol had to be dissolved in phosphate buffer containing volume fraction of 10 and $50 \%$ methanol $(\mathrm{MeOH})$. Deionized water $(\rho=18.3 \mathrm{M} \Omega$ $\mathrm{cm}$ ) obtained with a Milli-Q ${ }^{\circledR}$ water purification system from Merck (Darmstadt, Germany) was used for the preparation of phosphate buffer.

\section{Pretreatment of boron-doped diamond electrode}

A commercially purchased boron-doped diamond electrode (BDDE) with boron to carbon ratio of 1:1000 and a surface diameter of $3 \mathrm{~mm}$ (Windsor Scientific Ltd, Slough, UK) was used for all experiments. The BDDE surface was mechanically pretreated by carefully polishing it with a wet filter paper to eliminate the passivation layers on the electrode caused by oxidation products of polyphenols.

\section{Instrumentation}

The electrochemical behaviour of the dominant thirteen substances with antioxidant effect present in chocolate and Trolox was studied using cycling voltammetry at BDDE which was simultaneously connected with a silver/silver chloride electrode, $3.0 \mathrm{~mol} / \mathrm{L} \mathrm{KCl}$ as salt bridge (reference electrode) from Metrohm Česká republika s.r.o. (Prague, Czech Republic) and platinum sheet (auxiliary electrode) from Elektrochemické detektory, s. r. o. (Turnov, Czech Republic) to the potentiostat/galvanostat Autolab PGSTAT101 operated via the Nova 1.11 software from the above-mentioned Metrohm company (17).

Flow injection analysis (FIA) configuration consisted of a multi-channel peristaltic pump MINIPULS 3 from Gilson (Middleton, WI, USA), Rheodyne automatic six-position dosing valve from IDEX Health \& Science (Wertheim, Germany), and BDDE inserted into the cross-flow cell from Inventek Sp. z o.o. (Warsaw, Poland), as shown in Fig. 1.

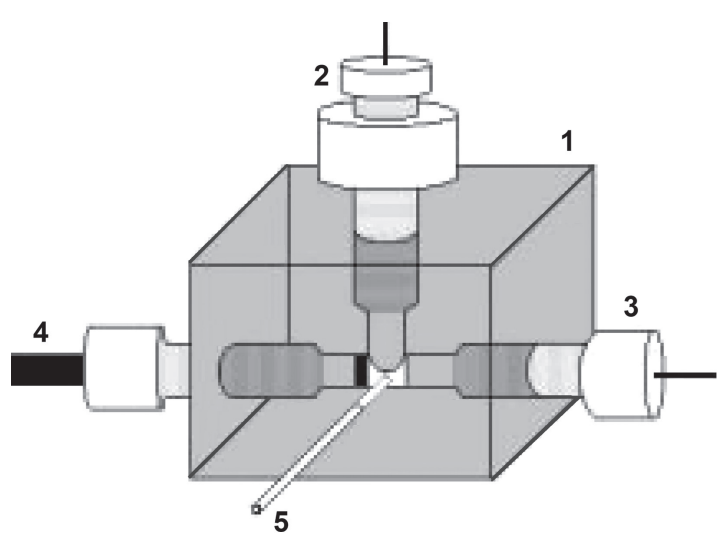

Fig. 1. Schematic diagram of the electrochemical flow cell used in the amperometric measurements in flow injection system: $1=$ polyurethane resin block, $2=$ silver chloride reference electrode, $3=$ auxiliary platinum electrode, $4=$ boron-doped diamond electrode, and $5=$ polyethylene tubing

\section{Methods}

Repetitive cyclic voltammetry (five cycles) was used to determine oxidation peak potentials of the investigated antioxidant substances. Potential range was set from -0.4 to $+1.6 \mathrm{~V}$, initial potential of $0 \mathrm{~V}$, scan rate (v) $50 \mathrm{mV} / \mathrm{s}$, and potential step $\left(E_{\text {step }}\right) 2.5 \mathrm{mV}$. Flow injection analysis with amperometric detection in the wall-jet configuration was usually performed at $+1.3 \mathrm{~V}$ vs a miniature silver/silver chloride reference electrode at flow rate of $1 \mathrm{~mL} / \mathrm{min}$. The $0.1 \mathrm{~mol} / \mathrm{L}$ phosphate buffer $(\mathrm{pH}=7.0)$ containing $30 \%$ methanol was used as 
flowing carrier solution. Otherwise, all necessary changes in the working conditions are listed in the legends of the corresponding figures.

\section{Sample preparation}

Several purposefully selected chocolates of imported origin, differing in the cocoa solid content from 0 to $80 \%$, were purchased from common stores in Prishtina, Kosovo. The extraction of potential antioxidants from the chocolate samples of $5 \mathrm{~g}$ containing different amounts of cacao were carried out in a total mixture of $50 \mathrm{~mL}$ of water (70\%), acetone (29.8\%) and glacial acetate acid $(0.2 \%)$ using the ultrasonic bath at $30{ }^{\circ} \mathrm{C}$ for $30 \mathrm{~min}$. The acetone was evaporated in ultrasonic bath at $40^{\circ} \mathrm{C}$ for $20 \mathrm{~min}$. After this, the solution with chocolate was adjusted with $0.1 \mathrm{~mol} / \mathrm{L} \mathrm{NaOH}$ to $\mathrm{pH}=5$ and diluted in 100-mL volumetric flask using $0.1 \mathrm{~mol} / \mathrm{L}$ phosphate buffer $(\mathrm{pH}=7.0)$ and $\mathrm{MeOH}(\varphi=30 \%)$. The sample was then centrifuged five times at stirring speed of $1000 \mathrm{rpm}$ for $4 \mathrm{~min}$ and filtered through a filter paper of pore size less than $1 \mu \mathrm{m}$. The filtrate obtained from the chocolate extracts was diluted fivefold to reduce the high content of extract-reducing agents. Sample volume of $100 \mu \mathrm{L}$ was used for FIA analysis.

\section{Statistical evaluation}

Analysis of chocolate extracts was always repeated five times $(N=5)$ and final results were calculated and presented as error bars (confidence intervals) $\bar{x} \pm s t_{1-a}$, where $\bar{x}$ is the arithmetic mean, $s$ the standard deviation, and $t_{1-a}$ the critical value of Student's $t$-distribution for five (4 degrees of freedom) determinations (2.7764) at a significance level $\alpha=0.05$ (95\% probability).

\section{RESULTS AND DISCUSSION}

\section{Electrochemical behaviour of substances present in chocolate}

In this work we investigated only the reducing power of the chocolate samples, i.e. the potential of a substance to reduce another substance either by removal of hydrogen atom or release of electrons. We did not use conventional spectrophotometric assays, which are based on monitoring the reactions between the present antioxidants and 2,2'-azino-bis(3-ethylbenzothiazoline-6-sulfonic acid (ABTS ${ }^{+}$) or di(phenyl)-(2,4,6-trinitrophenyl) iminoazanium (DPPH') radicals.

Since we can anodically oxidise most of the chocolate components with antioxidant activity at carbon-based working electrodes (18-20), we investigated the electrochemical behaviour of thirteen selected antioxidants using repetitive cyclic voltammetry (five cycles) at BDDE in $0.1 \mathrm{~mol} / \mathrm{L}$ phosphate buffer $(\mathrm{pH}=7.0$ ) from 0 to $+1.6 \mathrm{~V}$ and back to $0.4 \mathrm{~V}$. Due to low water solubility, phosphate buffer with $\mathrm{MeOH}(\varphi=10 \%)$ was used for electrochemical study of (+)-catechin, (-)-epicatechin and naringin, while addition of $50 \% \mathrm{MeOH}$ was necessary for kaempferol due to its low solubility in water.

To set a constant working potential for the subsequent amperometric detection, it was important to determine the values of the peak potentials of individual antioxidants. All investigated antioxidants provided minimally one oxidation peak, where for the analytical purpose (determination of cocoa powder content in chocolate), peak potential values of the first peaks are shown in ascending order as follows: caffeic acid at $+0.398 \mathrm{~V}$, kaempferol at $+0.483 \mathrm{~V}$, chlorogenic acid at $+0.505 \mathrm{~V}$, sinapic acid at $+0.620 \mathrm{~V}$, gallic acid at $+0.635 \mathrm{~V}$, $(+)$-catechin at $+0.640 \mathrm{~V}$, L-ascorbic acid at $+0.649 \mathrm{~V}$, vanillin at $+0.688 \mathrm{~V},(-)$-epicatechin at $+0.744 \mathrm{~V}$, naringin at $+1.011 \mathrm{~V}$, cinnamic acid at $+1.133 \mathrm{~V}$, caffeine at $+1.384 \mathrm{~V}$, and theobromine (TBR) at $+1.404 \mathrm{~V}$.

For demonstration, repetitive cyclic voltammograms ( 5 cycles) of Trolox, vanillin, and TBR are shown in Fig. 2. In all cases, a decrease in the oxidation signal was observed with each subsequent cycle, indicating a slow transport of oxidation products from the BDDE surface. This phenomenon was solved when these products were flushed from the electrode surface by amperometric detection in a flow mode. From the above-mentioned peak potential values, it is clear that if a constant potential is set for amperometric detection of $+0.623 \mathrm{~V}$ (Trolox), antioxidants having higher oxidation peak
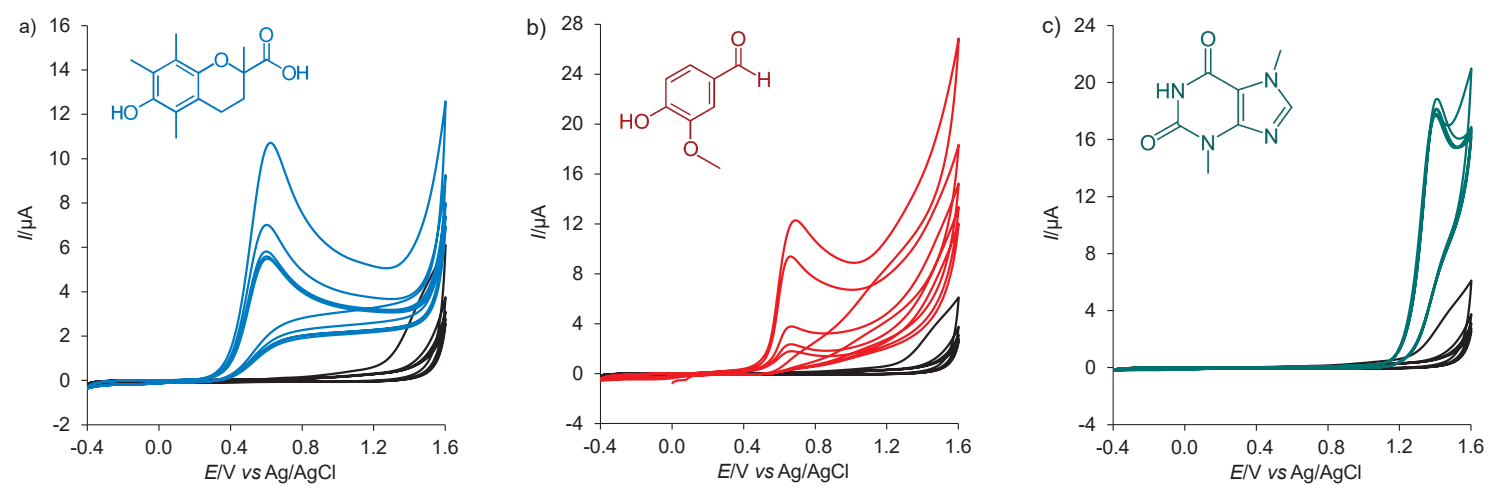

Fig. 2. Repetitive cyclic voltammograms (5 cycles) of: a) $1 \mathrm{mmol} / \mathrm{L}$ Trolox, b) vanillin, and c) theobromine recorded on boron-doped diamond electrode in $0.1 \mathrm{~mol} / \mathrm{L}$ phosphate buffer $(\mathrm{pH}=7.0)$ at a scan rate of $50 \mathrm{mV} / \mathrm{s}$. Black curves (blank) indicate the cyclic voltammograms obtained for phosphate buffer only 
potentials will not be included in chocolate analysis. Hence, an effect of amperometric detection on total antioxidant content (TAC) values was essential for optimisation. These TAC values are usually expressed as Trolox equivalent antioxidant capacity (TEAC) (21). The presence of short-chain alcohols in phosphate buffer (aqueous-alcoholic mixtures) generally has no effect on peak shift. However, this assumption had to be verified for a $\mathrm{MeOH}$ volume fraction of 10 to $50 \%$.

\section{Optimisation of flow injection analysis}

The optimisation procedure included selection of optimal working parameters, such as composition of carrier solution, potential of amperometric detection, and flow rate. Due to the presence of slightly water-soluble phenolic acids, flavonoids and tannins, it was necessary to select the $\mathrm{MeOH}$ volume fraction in the carrier solution of $0.1 \mathrm{~mol} / \mathrm{L}$ phosphate buffer ( $\mathrm{pH}=7.0)$. The whole optimisation was carried out in the dark chocolate extract with $w$ (cocoa) $=80 \%$.

In general, polyphenolic compounds can be defined as weak organic acids for which it is known that their peak potentials are shifted to more positive potentials with decreasing $\mathrm{pH}$ values $(22,23)$. The main reason for not performing FIA with acidic carrier solution is the necessity of amperometric detection at high positive potentials. The effect of $\mathrm{pH}$ in a range of $\mathrm{pH}=6-9$ on current response of $1 \mathrm{mmol} / \mathrm{L}$ Trolox was investigated using cyclic voltammetry in $0.1 \mathrm{~mol} / \mathrm{L}$ phosphate buffer. The obtained results indicate that the Trolox provides the maximum current response at $\mathrm{pH}=7$, which was consistent with other studies that report the determination of polyphenols using FIA $(24,25)$.

The optimum volume fraction of methanol in the carrier phosphate buffer solution was determined by varying $\varphi(\mathrm{MeOH})=0-50 \%$. For constant detection potential of $+1.3 \mathrm{~V}$ and flow rate of $1 \mathrm{~mL} / \mathrm{min}$, the extract of dark chocolate provided an oxidation peak whose height increased with higher volume fractions of $\mathrm{MeOH}$ (up to $30 \%$ ) in the phosphate buffer (Fig. 3) and this was taken as an optimum for further measurements.

Retaining the detection potential constant throughout the analysis is of critical significance for the application of amperometric sensing. After injection of the chocolate extract into the flowing carrier solution, an evident increase in the current response became clear for potentials greater than $+0.7 \mathrm{~V}$, whereas setting at higher potential values triggered only a small increase in the current response. However, a significant increase in the baseline current response was observed at detection potentials greater than $+1.4 \mathrm{~V}$ and thus the optimal value of $+1.4 \mathrm{~V}$ was chosen for preventive purposes.

The carrier solution flow rate was also the important FIA working parameter to be optimised as it specifies the duration of reducing agents (polyphenols) in the column where their electrochemical oxidation takes place. The flow rate of

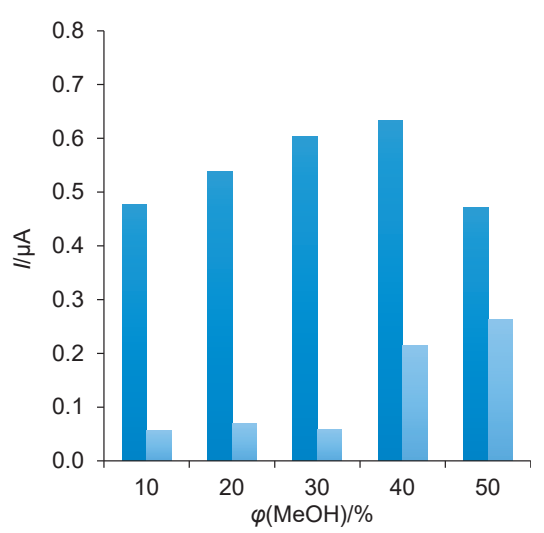

Fig. 3. Effect of $\mathrm{MeOH}$ volume fraction in phosphate buffer on the current response of the extract of dark chocolate with $w($ cocoa $)=80$ $\%$. Results were recorded on boron-doped diamond electrode in FIA mode at a flow rate of $1 \mathrm{~mL} / \mathrm{min}$ and detection potential of $+1.3 \mathrm{~V}$. The light blue bars indicate the baseline current responses

0.2 to $1.6 \mathrm{~mL} / \mathrm{min}$ for $50 \mathrm{mg} / \mathrm{L}$ Trolox was investigated at the fixed potential of $+1.3 \mathrm{~V}$. A sharp rise in peak height was seen up to $1 \mathrm{~mL} / \mathrm{min}$, while a constant current response was observed above that flow rate. Therefore, a flow rate of $1 \mathrm{~mL} /$ min was chosen as optimum.

\section{Analytical method validation}

First, it is necessary to note that the presented contribution is not an introduction of a newly developed analytical method for TEAC determination of chocolate extracts, but an initial study to find out whether TEAC values can be used as a marker for cocoa content in chocolate samples. However, a simple validation of FIA with amperometric detection at BDDE had to take place.

Precision, defined as the level of agreement of repeated measurements, was determined as relative standard deviation (RSD) of five analyses (injections). For example, RSD values of 3.3 and $3.8 \%$ for milk chocolate (30 \% cocoa) and dark chocolate (50\% cocoa) extracts, respectively, were calculated. If significance level of $5 \%(\alpha=0.05)$ is taken into account, satisfactory precision can be obtained.

As shown in Fig. 4, the dependence of height of oxidation current on Trolox concentration was studied for calibration range from 5 to $160 \mathrm{mg} / \mathrm{L}$. A calibration range from 5 to 100 $\mathrm{mg} / \mathrm{L}$ Trolox was described by the following equation:

$$
I=0.04859+0.0233 c \quad \mathrm{R}^{2}=0.9994
$$

where 0.04859 is a slope characterising the sensitivity, 0.0233 is $y$-intercept, and $c$ is the concentration of the standard (Trolox). This linear behaviour between Trolox concentration and peak current response can be applicable for analytical purpose. If concentrations higher than 100 to $160 \mathrm{mg} / \mathrm{L}$ Trolox are included into calculations of linear regression, the following equation will be obtained:

$$
I=0.05736+0.0211 c \quad R^{2}=0.9954
$$

where 0.05736 is the slope, and 0.0211 is $y$-intercept. Due to the high value of the intercept, it was not possible to use the 
method of standard addition, and therefore method of calibration curve was preferred. Limit of detection (LOD) and limit of quantification (LOQ) of 1.4 and $4.6 \mathrm{mg} / \mathrm{L}$ Trolox, respectively, were calculated according to the formulae:

$$
\mathrm{LOD}=3 \mathrm{~s} / \mathrm{k}
$$

and

$$
\mathrm{LOQ}=10 \mathrm{~s} / \mathrm{k}
$$

where 3 and 10 are statistically recommended multiples of the baseline noise, $s$ represents the standard deviation of five repetitive measurements of $5 \mathrm{mg} / \mathrm{L}$ Trolox and $k$ is the slope of linear regression (0.0233).

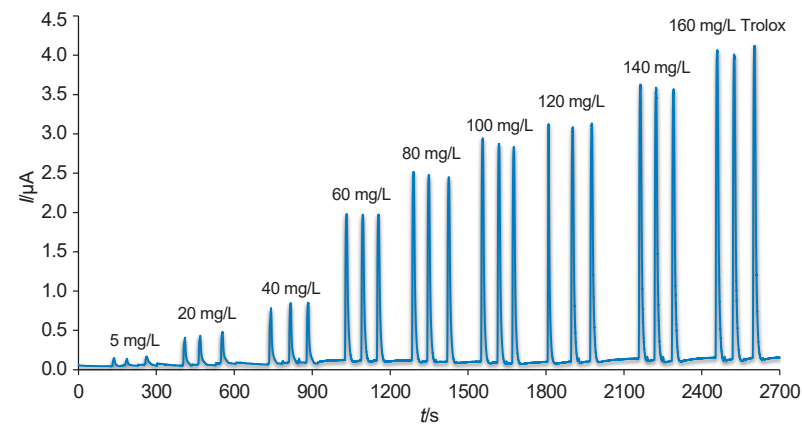

Fig. 4. Typical amperograms of flow injection analysis recorded on boron-doped diamond electrode within calibration measurements at optimum working conditions (phosphate buffer with $\varphi(\mathrm{MeOH})=30$ $\%$, flow rate of $1 \mathrm{~mL} / \mathrm{min}$ and detection potential of $+1.3 \mathrm{~V}$ )

\section{Analysis of chocolate samples}

Extracts of white chocolate (0\% cocoa), two samples of milk chocolate (30\% cocoa), and three dark chocolates (50, 64 and 80 \% cocoa) were analysed using FIA at BDDE. Two milk chocolates from different manufacturers with the same cocoa mass fraction were chosen to verify the accuracy of the analysis. Fig. 5 shows that both extracts of milk chocolates provided comparable current response. In addition, a current response at the limit of detection was obtained for the extract of white chocolate which confirms that this type of chocolate cannot be considered as a rich source of antioxidants.

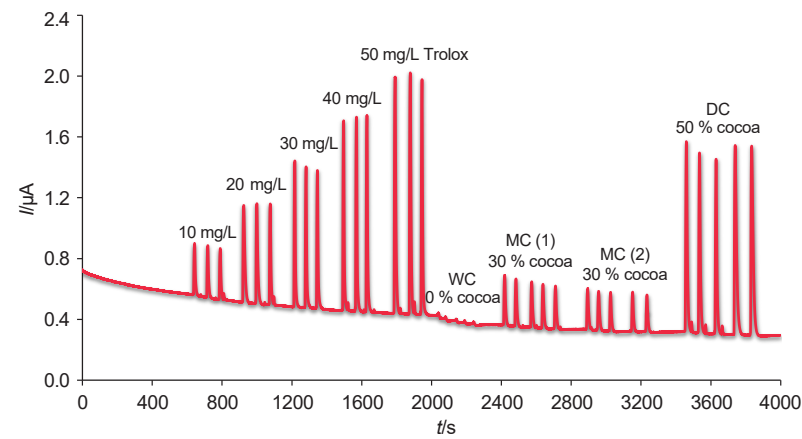

Fig. 5. Typical record obtained during flow injection analysis of white (WC), milk (MC) and dark chocolate (DC) at the boron-doped diamond electrode
Unlike this, the dark chocolate extract samples were diluted twice so that their current responses would not exceed the linear range.

Except for one sample of chocolate with $80 \%$ cocoa (excluded from statistical evaluation), TEAC values (mg Trolox per $100 \mathrm{~g}$ sample) increased with higher cocoa mass fraction. The reason why the dark chocolate extract provided the current response like chocolate samples with half the cocoa content has not been further investigated. However, it can be assumed that the manufacturer probably declared false nutritional information.

Fig. 6 shows that TAC presented as TEAC could be considered as additional marker of cocoa content in the chocolate analysis to the commonly used TBR and caffeine (7). Moreover, a high positive correlation between the determined TEAC values and cocoa mass fractions characterised by $\mathrm{R}=0.9187$ for eight randomly selected chocolate samples is proof of that. The calculated TEAC values from FIA are in close agreement with those previously reported routine spectrophotometric assays that are usually based on the reaction of antioxidants with a colour radical $(26,27)$.

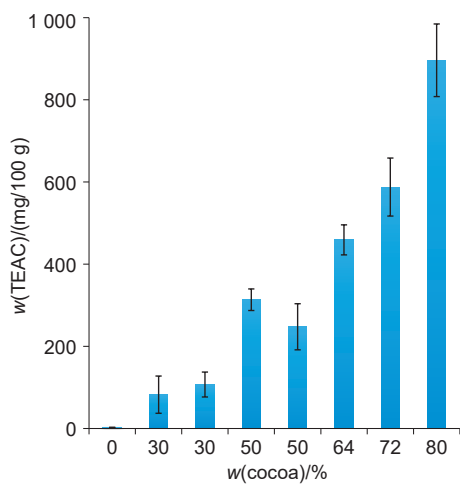

Fig. 6. Trolox equivalent antioxidant capacity (TEAC) of white (0\%), milk (30\%), and dark (50-80 \% cocoa mass fraction) chocolates obtained using the flow injection analysis with integrated boron-doped diamond electrode

\section{CONCLUSIONS}

The boron-doped diamond electrode integrated in the flow injection analysis (FIA) system could represent a simple analytical tool for evaluation of chocolate quality by determining its cocoa content. This basic study represents the first step in the development of a simple analytical method for determination of cocoa content as a source of polyphenols and other potential antioxidants (reducing agents). It is expected that the analyses of more chocolate samples containing different cocoa powder mass fractions and comparisons with measured total phenolic content as Trolox equivalents will be the subjects of the upcoming investigations. The developed FIA will find application in the food quality control if the presented assumption is confirmed. 


\section{ACKNOWLEDGEMENTS}

Financial supports from the Faculty of Chemical Technology, University of Pardubice (project No. SGS-2020-002) and mobility support from CEEPUS network CIII-CZ-0212-13-1920 are gratefully acknowledged.

\section{FUNDING}

This research received no external funding.

\section{CONFLICT OF INTEREST}

All authors declare that they do not have any known competing financial interests or personal relationships that could have appeared to influence the work reported in this paper.

\section{AUTHORS' CONTRIBUTION}

T. Arbneshi evaluated the measured data. A. Frangu carried out all laboratory measurements. M. Frühbauerová prepared samples of chocolates for FIA analysis. L. Červenka made the final correction of the English language. L. Berisha constructed an electrochemical flow cell. K. Kalcher designed all steps leading to the development of the present electroanalytical method. M. Sýs coordinated the work of the whole scientific team and wrote the manuscript.

\section{ORCID ID}

T. Arbneshi $\odot$ https://orcid.org/0000-0003-3053-169X

A. Frangu (i) https://orcid.org/0000-0001-9525-8466

M. Frühbauerová @is https://orcid.org/0000-0003-1286-7341

L. Červenka (1) https://orcid.org/0000-0003-2316-8765

L. Berisha (1) https://orcid.org/0000-0003-3516-0314

M. Sýs ๑ https://orcid.org/0000-0002-3982-3659

\section{REFERENCES}

1. Aprotosoaie AC, Luca SV, Miron A. Flavor chemistry of cocoa and cocoa products - An overview. Compr Rev Food Sci Food Saf. 2016;15(1):73-91.

https://doi.org/10.1111/1541-4337.12180

2. Montagna MT, Diella G, Triggiano F, Caponio GR, De Giglio O, Caggiano G, et al. Chocolate, "Food of the Gods": History, science, and human health. Int J Environ Res Public Health. 2019;16(24):4960.

https://doi.org/10.3390/ijerph16244960

3. Katz DL, Doughty K, Ali A. Cocoa and chocolate in human health and disease. Antioxid Redox Signal. 2011;15(10):2779_ 811.

https://doi.org/10.1089/ars.2010.3697

4. Directive 2000/36/EC of the European Parliament and of the Council relating to cocoa and chocolate products intended for human consumption. Off J Eur Comm. 2000;L197: 19-25. Available from: https://eur-lex.europa.eu/LexUriServ/LexUriServ.do?uri=OJ:L:2000:197:0019:0025:EN:PDF.
5. Code of Federal Regulations (CFR). Title 21: Food and drugs. Part 163-Cacao products, Subpart B-Requirements for specific standardized cacao products, Paragraph 163.123 Sweet chocolate. Washington, DC, USA: US Government Publishing Office; 2019. pp. 546-7. Available from: https:// www.govinfo.gov/content/pkg/CFR-2020-title21-vol2/pdf/ CFR-2020-title21-vol2-part163.pdf.

6. Kopriva P. As good as half of the cocoa content was missing in instant drink MalCao. Brno, Czech Republic: Czech Agriculture and Food Inspection Authority (CAFIA); 2016. Available from: https://www.szpi.gov.cz/en/article/as-good-ashalf-of-the-cocoa-content-was-missing-in-instant-drinkmalcao.aspx?q=JmNobnVtPTEmaGw9Y29jb2E\%3d.

7. Risner $\mathrm{CH}$. Simultaneous determination of theobromine, (+)-catechin, caffeine, and (-)epicatechin in standard reference material baking chocolate 2384 , cocoa, cocoa beans, and cocoa butter. J Chromatogr Sci. 2008;46(10):892-9.

https://doi.org/10.1093/chromsci/46.10.892

8. ČSN 56 0578. Chocolate and chocolate confectionery Determination of fat-free cocoa solids. Prague, Czech Republic: Czech technical standards (ČSN); 2017 (in Czech). Available from: https://www.technickenormy.cz/csn-560578-cokolada-a-cokoladove-cukrovinky-stanoveni-obsahu-tukuproste-kakaove-susiny-1/.

9. Steinberg FM, Bearden MM, Keen CL. Cocoa and chocolate flavonoids: Implications for cardiovascular health. J Am Diet Assoc. 2003;103(2):215-23.

https://doi.org/10.1053/jada.2003.50028

10. Genovese MI, da Silva Lannes SC. Comparison of total phenolic content and antiradical capacity of powders and "chocolates" from cocoa and cupuassu. Food Sci Technol. 2009;29(4):810-4.

https://doi.org/10.1590/S0101-20612009000400017

11. Švorc L, Tomčík P, Svítková J, Rievaj M, Bustin D. Voltammetric determination of caffeine in beverage samples on bare boron-doped diamond electrode. Food Chem. 2012;135(3): 1198-204.

https://doi.org/10.1016/j.foodchem.2012.05.052

12. Farag AS, Sýs M, Hájek T, Vytřas K. Voltammetric determination of ethylvanillin and methylvanillin sum at carbon paste electrode modified by sodium dodecyl sulfate in selected foodstuffs. Monatsh Chem. 2018;149:1945-53.

https://doi.org/10.1007/s00706-018-2266-z

13. Brcanović JM, Pavlović AN, Mitić SS, Stojanović GS, Manojlović DD, Kaličanin BM, Veljković JN. Cyclic voltammetric determination of antioxidant capacity of cocoa powder, dark chocolate and milk chocolate samples: Correlation with spectrophotometric assays and individual phenolic compounds. Food Technol Biotechnol. 2013;51(4):460-70.

14. Švorc $L$, Haššo $M$, Sarakhman $O$, Kianičková $K$, Stanković DM, Otřísal P. A progressive electrochemical sensor for food quality control: Reliable determination of theobromine in chocolate products using a miniaturized boron-doped 
diamond electrode. Microchem J. 2018;142:297-304.

https://doi.org/10.1016/j.microc.2018.07.007

15. Dejmkova H, Scampicchio M, Zima J, Barek J, Mannino S. Determination of total phenols in foods by boron doped diamond electrode. Electroanalysis. 2009;21(9):1014-8. https://doi.org/10.1002/elan.200804508

16. Akoglu H. User's guide to correlation coefficients. Turk J Emerg Med. 2018;18(3):91-3. https://doi.org/10.1016/j.tjem.2018.08.001

17. Nova, v. 1.11.0, Metrohm Autolab B.V., Utrecht, The Netherlands; 2014. Available from: http://www.ecochemie.nl/ news/NOVA_1.11.html.

18. Pekec B, Feketeföldi B, Ribitsch V, Ortner A, Kalcher K. Development of an electrochemical sensor for the determination of the total antioxidant capacity in berries based on boron doped diamond. J Electrochem Sci Eng. 2013;3(1):1-9. https://doi.org/10.5599/jese.2012.0024

19. Alpar N, Yardım Y, Șentürk Z. Selective and simultaneous determination of total chlorogenic acids, vanillin and caffeine in foods and beverages by adsorptive stripping voltammetry using a cathodically pretreated boron-doped diamond electrode. Sens Actuators B Chem. 2018;257:398408.

https://doi.org/10.1016/j.snb.2017.10.100

20. Jiang L, Ding Y, Jiang F, Li L, Mo F. Electrodeposited nitrogen-doped graphene/carbon nanotubes nanocomposite as enhancer for simultaneous and sensitive voltammetric determination of caffeine and vanillin. Anal Chim Acta. 2014;833:22-8. https://doi.org/10.1016/j.aca.2014.05.010

21. Miller NJ, Rice-Evans C, Davies MJ, Gopinathan V, Milner A. A novel method for measuring antioxidant capacity and its application to monitoring the antioxidant status in premature neonates. Clin Sci. 1993;84(4):407-12.

https://doi.org/10.1042/cs0840407

22. Macikova P, Halouzka V, Hrbac J, Bartak P, Skopalova J. Electrochemical behaviour and determination of rutin on modified carbon paste electrodes. Sci World J. 2012;2012:Article ID 394756.

https://doi.org/10.1100/2012/394756

23. Chao M, MaX. Voltammetric determination of chlorogenic acid in pharmaceutical products using poly(aminosulfonic acid) modified glassy carbon electrode. J Food Drug Anal. 2014:22(4):512-9.

https://doi.org/10.1016/j.jfda.2013.12.006

24. Leamsomrong K, Suttajit M, Chantiratikul P. Flow injection analysis system for the determination of total phenolic compounds by using Folin-Ciocalteu assay. Asian J Appl Sci. 2009;2(2):184-90.

https://doi.org/10.3923/ajaps.2009.184.190

25. Freitas JM, da Costa Oliveira T, Munoz RAA, Richter EM. Boron doped diamond electrodes in flow-based systems. Front Chem. 2019;7:190.

https://doi.org/10.3389/fchem.2019.00190

26. Calixto-Cotos MR, Chire-Fajardo GC, Orihuela-Rivera CA. Antioxidants properties of chocolates sold in Peru. Acta Agron. 2018;67(4):479-85.

https://doi.org/10.15446/acag.v67n4.71357

27. Godočiková L, Ivanišová E, Árvay J, Petrová J, Kačániová M. The comparison of biological activity of chocolates made by different technological procedures. Potr S J F Sci. 2016; 10(1):316-22.

https://doi.org/10.5219/628 